\title{
REFLEXIONES SOBRE LA APORIA REALISMO-IDEALISMO
}

El encuentro del hombre, en su espontánea actitud conocitiva, con un conjunto de manifestaciones distintas a él, es decir, con un mundo "externo", y con una serie de vivencias y elementos propios, personales, es decir, con un "mundo interno", ha significado, sin duda, desde la primera aparición aún rudimentaria de la conciencia, un conflicto, una contrariedad, un problema, a causa de las profundas dificultades halladas para entender la correspondencia, reducción, eventual aplicación, entre esos mundos: conflicto que en algunos ha desembocado tal vez en el atisbo de la presencia de una verdadera aporía.

El mundo externo y el mundo interno, lo objetivo y lo subjetivo, lo empírico y lo a priori, lo real y lo ideal, lo abstracto y lo concreto, lo existente y lo "apareciente", lo fenoménico y lo nouménico, el ser y el pensamiento -o cualesquiera otras denominaciones más o menos equivalentes que se les dé- implican o parecen implicar una oposición tan radical, irreductible, contradictoria y excluyente, que a través de la historia del pensamiento produjo y mantiene el par de ismos opuestos quizá más relevante: el de realismo-idealismo. Las dos actitudes se apoyan en fundamentos teóricos y empíricos, que en principio pueden considerarse como indubitables; lo cual precisamente haría pensar que se trata de un falso problema, de un defecto de perspectiva, o de los polos de una antinomia. Porque, en primer lugar, la oposición misma en cuanto tal no es la causa del problema, ya que ella es algo natural - lo que en último término se funda en la dualidad y alteridad de los elementos conocitivos, es decir, el objeto y el sujeto-, en vista de que las características de los factores opuestos son esenciales, definitorias.

Por otra parte, la existencia en cuanto tal, correlacionada y aun correspondiente, de los dos aspectos, no sólo no es conflictiva de por sí, sino que es necesaria; e incomprensible sería más bien la no-coexistencia. Que algo sea real y algo diverso y opuesto sea ideal; que exista algo subjetivo y algo objetivo; que haya algo empírico y algo a priori, etc.: todo esto nadie podrá negarlo, una vez bien definidos los términos. La dificultad estriba más bien en atros puntos. Los principales, a mi juicio, son dos: primero, la eliminación llana y simple de un aspecto, reduciendo el otro a éste - pueden servir de ejemplos el empirismo, el fenomenismo o los idealismos radicales de Platón y Berkeley-, y segundo, la sustitución o suplantación de un aspecto con otro, sin negar necesariamente el primero, o, dicho en diversa forma, la atri- 
bución de las características propias del uno al otro -como sería, considerando las formulaciones de Kant, un realismo trascendental (=aristotélicoescolástico) y un idealismo empirico o material. Tanto la eliminación y la sustitución, como cualesquiera otras actitudes que pretendan soslayar el problema planteado por la oposición natural entre los dos aspectos, desembocan en teorías que por principio se cierran la puerta a la posible solución, o cuando menos al reconocimiento de una aporía, de una antinomia.

A mi juicio, las posiciones gnoseológicas realismo-idealismo -así en cuanto ismos y en cuanto teorias explicativas, no como meras comprobaciones de fenómenos- derivan histórica y doctrinalmente del problema que existió siempre acerca del origen, de la causa y "localización" de las determinaciones formales y materiales que ofrece la realidad (ejemplo plástico de esta diferencia sería una cosa de un metal concreto $=$ determinación material, y con una figura particular = determinación formal). No es difícil advertir que todo realismo, en general, sostiene que esas determinaciones precisamente "se hallan" en la realidad, de donde proceden para la mente; mientras que todo idealismo, en general, sostiene que tales determinaciones son función y producto de la facultad conocitiva.

Ahora bien, el problema no se refiere a la aportación específica que es atribuida a cada factor, ya que el conocimiento, según los datos fenoménicos, siendo por una parte un acto y teniendo por otra un contenido, ofrece necesariamente un aspecto mental estructural e ideal y otro aspecto diverso del acto y de la estructura ideal por cuyo medio es conocido, independiente en tal forma, y por lo mismo real. Es decir, fenoménica y provisionalmente al menos, no puede negarse que lo "real", la realidad, aporte algo en or. den al conocimiento, así como lo hacen las estructuras ideales de la facultad conocitiva: esto segundo parece imposible que alguien lo niegue, si no como "ideas" estrictamente dichas, sí al menos como instrumentos conocitivos; para lo primero, basta la evidencia de que la facultad conocitiva no puede ni imaginar ficticiamente, ni deducir lógicamente, ni crear entitativamente el contenido u objeto último e irreductible del conocimiento: en el primer caso se trataría de una ilusión o apariencia; en el segundo, de una pura construcción mental; en el tercero, de una acción y un efecto negados por principio al ser finito.

El problema, que ahora enfocamos muy sumariamente, más bien se refiere en general a la atribución no específica o invertida de los elementos determinativos a uno de los factores en vez del otro. Los elementos determinativos serían de dos clases: de simple "determinación" de la pura existencia - cuasi determinación - y de determinación propiamente dicha, formal y categorial. Todo realismo falso o infundado deriva de una atribución absoluta del segundo tipo de elementos a Ia "realidad"; en forma parecida, todo idealismo falso o infundado deriva de una atribución también absoluta, a 
las estructuras ideales o al acto y a la función gnoseológicos de la mente, de cualquier materia o sustrato entitativo, 1 que resolviera el problema aludido antes, el cual deriva de la imposibilidad de reducir el conocimiento a una ficción, deducción o creación. En cierta forma hay una atribución total de las dos clases de elementos ora a uno, ora a otro de los aspectos o factores.

II

Acerca de este problema, el ordinario realismo tradicional resulta ingenuo y con bases empiristas y positivistas. Su tesis se reduce en el fondo a la reafirmación o confirmación del dato fenoménico, semejante a los asertos que se hacen en el sistema tolemaico del mundo: el Sol sale, el Sol se pone, el Sol recorre el cielo. Para este realismo, en general, los objetos, los seres, son entitativamente como se nos manifiestan, tienen en sí y por sí no sólo las cualidades sensibles o sus fundamentos, sino las formas y estructuras mismas, es decir, las esencias, las formas sustanciales. El mundo empírico se convierte en mundo trascendente por un lado y en trascendental por otro; lo primero, por su existencia independiente en sí, y lo segundo, por la atribución a él de las estructuras formales. En términos estrictos, y con respecto a este problema, no parece posible considerarlo como teoría o explicación -a no ser en sentido impropio y no científico-, porque sólo afirma lo que percibe a primera vista: que las determinaciones manifestadas en el conocimiento están en los objetos, porque ahi las ve. En cierto modo, vistas las cosas así, ni se necesita explicación, excepto sólo ésta: que el conocimiento se reduce a la mera recepción, cual un espejo, de lo que es y existe en si perfectamente determinado, mediante una facultad dispuesta adecuadamente, a la que corresponde en el plano intelectivo sólo "abstraer" o sacar las formas y esencias, para que la mente, conforme a ellas, es decir, reproduciéndolas, realice sus funciones. Sin duda, esta tesis es luego desarrollada amplia y profundamente en aspectos conexos, pero el punto de partida permanece el mismo.

Ante esta posición, cabe preguntar de inmediato, ¿a qué se pretende reducir propiamente la labor y función de la facultad conocitiva, así sensible como intelectiva? Parece olvidarse del todo, por ejemplo, la evolucionadísima fisiología de los órganos sensoriales externos, sus complicados mecanismos y su admirable funcionamiento, por una parte; por otra, la finura, sutileza y diferenciabilidad de los procesos sensibles internos; pero, sobre todo, la casi infinita variedad, en grados y en especies, de actos, funciones y procesos intelectivos, que en principio, y con las debidas precisiones, obligan a atribuir a la facultad conocitiva la totalidad de las referencias o determinacio-

1 Siendo imposible no pensar o referirse de algún modo, aun el más impropio, lejano e indirecto, al elemento desconocido e inconocible -si fuera conocible, sería ya una determinación del conocimiento- que separa lo "existente" de lo no "existente", el "algo" de la "nada", me sirvo para tal efecto del término "entitativo". 
nes, ora configuradas y dispuestas por la sensibilidad, ora constituidas y expresadas por el entendimiento.

En cuanto a esto último, piénsese; también, en aquellas referencias 'o determinaciones mínimas, indefinidas, vagas y generales, que son como límite de las funciones del entendimiento, más allá de las cuales se hallaría el "sustrato entitativo informe", con el cual ellas precisamente nos permitirían el único nexo indirecto, convencional e hipotético. Me refiero a los términos "algo",. "nada", "ser", "cosa", "objeto", "ente", etc. ¿No son éstos concepciones del entendimiento y expresiones del lenguaje, actividad específica y exclusiva de la facultad conocitiva? En cuanto determinación formal o material, ¿sería posible señalar algo que en lo "real" correspondiera a estos términos?

Pero no sólo los términos anteriores -que desde un cierto punto de vista vienen a brindar un fácil argumento- sino cualesquiera otras expresiones concretas o particulares, como "hombre", "animal", "planta", "oro", "reloj", etc. Es indudable que a estos términos corresponde un objeto en la realidad, independientemente de la facultad que concibe, expresa y conoce. Pero, ¿de qué clase de "correspondencia" se trata? ¿De una formal y especifica, de modo que entre el conócimiento y la realidad hubiera la identificación de una imagen reflejada y de una estructura o esquema exactamente reproducido? (¿Es posible afirmar que hay una imagen o àlgo imaginable, si no se refleja? ¿O que hay una estructura o algo estructurable, si no se lo reproduce?) ¿O se trata más bien de una correspondencia con algo existente; informe sí, aunque capaz por él mismo, dentro del conocimiento, de producir sobre la facultad conocitiva una diversidad en las determinaciones? Podría tratarse de una diversidad potencial, conocible sólo a través de la diversidad en acto o producida. Tal vez, en efecto, quede mejor formulada esa correspondencia, si se la concibe como virtual o potencial, aun en orden a las determinaciones específicas, de manera que a toda determinación configurada o constituida, dentro del conocimiento, corresponda un elemento $\mathrm{X}$, informe $o$ indeterminado de por sí, pero formable y determinable en el conocimiento.

Aquí el problema último estaría en que, de cualquier modo, se atribuye a lo entitativo una diversidad especifica, que en alguna forma tiene que existir ahí, ya que la facultad conocitiva no puede ni fingir o inventar, ni deducir, ni crear el fundamento de la diversidad; es decir, el conocimiento no podria a su arbitrio decidir la presencia ora de una planta, ora de un hombre, ora de un libro, etc. O expresado con más exactitud: la evidente diversidad en los objetos presentes o manifiestos a la facultad conocitiva no puede ser únicamente su efecto, pues entonces no se explicaría la necesidad fáctica de la presencia de aquéllos, determinadamente dispuestos en el espacio y seguidos en el tiempo: en efecto, si el fundamento existiese en la 
facultad, la determinada disposición de los objetos en el espacio y la determinada sucesión de los mismos en el tiempo, dependerían sólo del propósito y exigencia del sujeto conocente: lo cual es del todo indemostrable. En suma, parece necesario admitir en la realidad unà diversidad especifica virtual, previa al conocimiento e independiente de éste, que explique la diversidad actual posterior, pero cuya actualización sea su único sentido y la única base, no sólo para saber de su existencia, sino simplemente para poder 'pensarla. En otras palabras, aunque entitativamente resulte necesario admitir eśa diversidad, sólo en orden al conocimiento y dentro de él tiene algún sentido y alguna validez el simple referirse a ella.

Veamos ahora directamente la posición del idealismo frente al problema planteado. La primera característica que debe atribuirse a éste, es el paso de la actitud directa a la actitud refleja: es decir, en vez de "teorizar" simplemente aquélla, concibe un verdadero sistema explicativo a partir de datos mínimos, pero suficientes. Su base y punto de arranque puede formularse así: siendo el conocimiento acto, proceso y función de un sujeto y teniendo en sí mismo los instrumentos necesarios para llevarlo a cabo, lo principal y decisivo es esto, y no lo diverso, ajeno y extraño a él - de lo cual, por otra parte, sólo puede ser consciente y hacerse responsable de modo indirecto. La actitud idealista, además, ostenta el sello de la madurez de conciencia y de reflexión, al trasladar toda la temática y problemática del conocimiento del plano natural y espontáneo de las cosas, los objetos, los seres, al plano teórico y reflejo de los procesos intélectivos así como de las estructuras ideales. En la actitud espontánea y natural basta, por decirlo así, abrir los ojos para tener las bases de la concepción entera; para la actitud refleja y teórica, en cambio, es preciso un gran esfuerzo -el esfuerzo copernicanoque se inició en Parménides y se concibió por vez primera en Platón, pero que para consumarse necesitó de los más grandes genios y' de la casi total historia del pensamiento. El idealismo, y los aspectos o tendencias idealistas de diversas teorías, representan la posición más "científica" y metódica, no sólo de la gnoseología, sino de la filosofía, tanto por emprender el camino más difícil, como por apoyarse en las bases más sólidas y llevar a cabo los análisis más profundos y las demostraciones más rigurosas.

Pero al idealismo le surgen dificultades también, aunque en una proporción y grado mucho menores por cierto que al realismo, con respecto al tema fundamental considerado aquí, a saber: el origen y la "localización" de las determinaciones del objeto del conocimiento. Este problema es, sin duda, el central de toda la gnoseología y sus consecuencias resultan decisivas no sólo para las demás disciplinas filosóficas, sino para las ciencias y el 
pensamiento humano entero. En torno a él han girado las reflexiones fundamentales de un Platón y un Kant, para no citar a otros, y constituye el punto esencial o clave del idealismo.

La pregunta y objeción básicas, que se han formulado desde sus comienzos al idealismo, se refieren a la verdadera y real existencia del mundo externo, diferente al sujeto. Porque, con base o sin ella, siempre se le ha atribuido la negación de éste. Sin embargo, en la mayor parte de los casos $\multimap$ en los más señalados: Platón, Descartes, Kant- puede demostrarse que dicha atribución se basa en un malentendido, en una confusión. En efecto, parece olvidarse que se trata de dos tipos de conocimiento, diversos y aun opuestos, y de dos clases de objetos, correspondientes a aquéllos: el conocimiento y mundo empírico frente al conocimiento y mundo ideal o a priori (trascendental). La confusión consiste en pretender, no tanto un conocimiento empírico del mundo ideal, cuanto lo contrario, un conocimiento trascendental del mundo empirico; es decir, se trataría de una aplicación invertida - de ahí la confusión - de una clase de conocimiento al objeto contrario, y viceversa.

En términos platónicos sería un conocimiento "ideico" o eidético del mundo sensible y una captación del mundo de las ideas por medio de los sentidos. En términos kantianos la inversión significaría, por un lado, un realismo trascendental, y por otro, un idealismo empirico: es decir, se pretendería, por una parte, un conocimiento intelectivo-intuitivo del dato o contenido de la intuición sensible (de ahí la negación radical kantiana de una "intuición intelectual", así entendida), ${ }^{2}$ y por otra parte, un conocimiento constitutivo mediante las categorías y conceptos del entendimiento por obra o a partir de la intuición sensible. La afirmación platónica de que el verdadero conocimiento y el verdadero mundo real es el de las ideas, debe entenderse precisamente en el sentido de que un conocimiento universalmente válido, inmodificable, permanente, eterno, etc., sólo es el que se obtenga por medio de las ideas, es decir, de instrumentos que posean esas características, y no con los sentidos, que tienen las contrarias. Lo cual, en primer término, viene a significar que, por falta de adecuación entre medios y objetos, no es posible lograr del mundo sensible un conocimiento con aquellas características y denominación, es decir, un conocimiento "verdadero".

Ahora bien, si se considera y define como conocimiento verdadero $y$ válido únicamente el de las ideas, no así el de los sentidos, en virtud de poseer o no las características aludidas, el problema se desplaza hacia el funda-

2 Fichte, tan idealista trascendental como Kant, 'sostiene una intuición intelectual, pero no orientada ni entendida así (lo que Kant no advirtió o no tuvo en cuenta), sino referida al acto de posición absoluta o al obrar puro del Yo: intuición que Fichte ve implícita en la apercepción trascendental de Kant. 
mento que se tenga para esa consideración y denominación. Con otras palabras se preguntaria: ¡es posible una justificación realmente fundada para llamar verdadero al conocimiento de las ideas y sólo aparente, y aun falso - bajo determinadas pretensiones - al de los sentidos? ¿No se ha advertido, desde siempre, una diferencia radical entre ambos conocimientos en lo que concierne a alcance, forma, métodos, etc., quedando para el eidético una primacia irreductible e indiscutible? Negar un conocimiento "verdadero" -en el sentido indicado- del mundo sensible, no es negar todo conocimiento del mismo.

En Platón el mundo sensible es un mundo percibido, conocido, aun dentro de todas las circunstancias negativas que se atribuyen al conocimiento de los sentidos o se dan en él. Las sombras percibidas en la caverna son lo que son percibidas y su diferencia respecto al "verdadero" conocimiento es sólo de especie o tipo, y aun de grado. Dentro del uso de la terminología moderna no puede sostenerse que Platón haya negado la existencia o presencia fenoménica del mundo externo sensible o empirico; lo que él le niega a éste es la existencia eidética y todas las características que ella implica, así como, en consecuencia, un conocimiento de él a priori, ideal, ontológico. Nadie sostiene un único modo de existir y conocer, cosa imposible e indemostrable dentro de las condiciones dadas de lo humano.

$\mathrm{Si}$, por tanto, existen dos modos fundamentales de conocer y dos objetos adecuados a ellos; si, además, cada uno reúne los requisitos específicos y necesarios para ponerse en relación, directa o indirecta, con la "realidad", cualquiera que ella sea; si, en fin, la diversidad entre ambos es tal que vienen a ser irreductibles y uno de ellos tiene características tan precarias, que pudo ser considerado - sin duda en sentido figurado e impropio- como noconocimiento o conocimiento sólo de lo aparente, irreal, inseguro, cambiante, efímero, etc.: entonces se deduce que la negación platónica del mundo real externo es sólo producto de una determinada perspectiva y de un modo especial de decir; también se deduce que el "idealismo" de las ideas no se contrapone - porque no está en el mismo nivel- con el "realismo" de las sensaciones.

La inversión de que hablamos antes puede considerarse mencionada expresa, aunque indirectamente, en la posición kantiano-fichteana de un idealismo trascendental y de un realismo empirico; menos indirectamente en la paralela refutación que hace Kant de un realismo trascendental y de un idealismo empírico, la cual se entiende fundada en tal inversión. Ahora bien, puede decirse que en los términos mismos está la clave para entender el sentido y validez de los argumentos. En efecto, parece evidente que un idealismo, por principio, no puede ser sino trascendental —si se toma este término y concepto en su verdadero sentido y valor $-;^{3}$ y que un realismo no

3 Cf. nuestro artículo: "Breve estudio sobre lo trascendental", en Diánoia, México, 1959, pp. 23-49. 
ha de ser sine empírico. Porquë lo expresado se halla implícito en la definición con bástante cláridad, a saber: que por medio de las:estructuras ideales es imposible tomar contacto con la realidad, pues no son adecuadas para captar lo real, precisamente por su carácter esquemático, estructural, abstracto (de ahí, por ejemplo, la invalidez del argumento llamado ontológico y la falta de alcance en las otras demostraciones de la existencia de Dios, por fundarse en un mero concepto $\ddot{y}$ carecer de una intuición empírica correspondiente); y en forma parecida, la intuición sensible, por significar un contacto directo e inmediato con algo y no necesitar de ninguna configuración estructural ${ }^{4}$ para el mismo, es la única que enlaza con lo real, no pudiendo, en cambio, tener relación alguna 'con estructuras ideales (dentro del realismo tradicional los conceptos referidos a objetos del-mundo externo son producto de una abstracción, es 'decir, en cuanto tales; prescinden de las notas individuantes concretas de lo real: por eso aun ellos tampoco son aptos para "demostrar" la realidad; de ahí el axioma: la realidad o existencia no se demuestra -mediante conceptos, juicios y raciocinios-, sólo se señala, se capta, se intuye).

Pero, además de las indicaciones anteriores, este punto de vista se confirma, si atendemos a la concepción de Kant sobre lo trascendental. En efecto, no sólo el perfil y la esencia de toda su gnoseología y: filosofía, sino las afirmaciones y aun definiciones expresas, sitúan absolutamente lo trascendental no en el campo directo "del conocimiento de cosas", sino en el reflejo del conocimiento del conocimiento mismo. Por consiguiente, toda referencia y' aplicáción de lo trascendental, según 'Kant, se hace sobre la esfera refleja de las estructuras y funciones intelectivas, y no sobre el mundo :directo de cosas y objetos, es decir, sobre la realidad (las expresiones kantianas: "realismo trascendental" y "objeto trascendental" se refieren a algo hipotético, es decir, a la cosa y realidad en sí, las cuales contendrían, independientemente del conocimiento, las estructuras formales significadas por lo trascendental).

Puede considerarse como una consecuencia de todo lo anterior, que existe una correlación o, más bien, un nexo o dependencia entre:el idealismo trascendental y èl realismo empírico, así como, paralela y opuestamente, entre el realismo trascendental y el idealismo empírico (sobre este segundo caso cf. la teoría aristotélico-escolástica en su concepto de la abstracción). Acerca del primer caso, Kant y Fichte lo dicen expresamente en muchos pasajes y demuestran esa necesaria correlación. ${ }^{5}$ Pero, además, ello está sin duda en el espíritu y sentido de toda su gnoseologia, expresado en aquel principio: los conceptos sin intuiciones son vacios; las intuiciones sin con-

4 Que signifique propiamente un intermediario, pues entonces ya no sería intuición, es decir, conocimiento inmediato.

5 Más adelante se ofrecen en forma directa y amplia sus puntos de vista. 
ceptos son ciegas. Es decir, ni.la intuición ni el concepto aislados son factores suficientes para un conocimiento verdadero y completo; es necesario reunirlos, complementarlos. El idealismo trascendental șolo ofrecería únicamente un mundo de luminosa claridad de estructuras ideales, conceptos, relaciones, categorías, esquemas, formas puras, etc., pero seria un tópos uránios, un mundo abstracto, teórico; irreal; el realismo empírico solo ofrecería únicamente una abigarrada y confusa multiplicidad de "impresiones", "sensaciones", "excitaciones", ."estímulos", etc., con el impacto poderoso e incontrolable de lo vivo, real y existente (algo así como lo que puede suponerse que aconteció al hombre primitivo o. sucede en los animales superiores, en lo que concierne al entendimiento); pero oscuros; nebulosos, informes, indeterminados.

Al realismo y al idealismo, por consiguiente, les: competen funciones diversas; en sus propios planos, no sólo no se oponen, contradicen :o eliminan, sino que son recíprocamente necesarios, pues. de otro modo se carecería de uno de :Ios dos factores del conocimiento como tal, que no es proceso pưro de la mente ni del sujeto, sino también aportación de la sensibilidad y del objeto: la intuición empírica debe aportar el 'contacto directo con "aquello" que es la realidad; las formas puras y las estructuras ideales deben aportar la configuración y.constitución de :aquélla, a fin. de que esa labor conjunta, como conocimiento, pueda ser incorporada a las funciones del ser pensante; a la vida del espíritu.

El realismo y el idealismo se oponen, y se invalidan a sí mismos, cuando abandonan los propios campos y olvidan el alcance de los propios instrumentos; cuando se autoatribuyen funciones y objetivos del todo infundados: básicamente, cuando el realismo atribuye a la "realidad" aquello que es sólo producto de la operación de la facultad conocitiva y cuạndo el idealismo atribuye a las estructuras y funciones de ésta:lo que es sólo aportación de la realidad. Entonces se llega - y ha llegado- a los límites de la indemostrabilidad y del dogmatismo, así como a reducir al'mínimo y hasta negar la presencia o aportación de uno de los dos factores: lo que en el fondo conduce a invalidar el conocimiento mismo.

\section{IV}

Tratándose del problema realismo-idealismo, es innegable que, si queremos tomar un punto de partida para la investigación en algún autor clásico, ha de recurrirse en primerísimo lugar a Kant $-y$ junto a él a Fichte, por la conexión inmediata de éste con la gnoseología trascendental de aquél. Én lo que concierne a Kant, creo que cualquiera justificación de esta actitud resulta superflua, si se conoce aunque sea de lejos y en general el contenido de la Critica de la razón pura; en lo que se refiere a Fichte, aparecerá como 
evidente para un buen conocedor de la filosofía fichteana y para quien estudie a fondo la Lógica trascendental, la Primera y Segunda Introducción a la teoria de la ciencia, ${ }^{6}$ etc.

La esencia de la gnoseología kantiana sobre el tema presente ${ }^{7}$ puede formularse así: idealismo en lo que se refiere a la realización y a la constitución misma del conocimiento, es decir, a los procesos intelectivos y a las estructuras ideales, y realismo en lo que concierne a la mera toma de contacto con lo existente, al simple y puro nexo con lo real; o, dicho más brevemente: es idealismo por lo que tiene y requiere de ideal, y realismo por lo que tiene y exige de real. De acuerdo con esto, no parecería haber mejor manera de expresar una tautología o de llevar implícito un raciocinio puramente analítico: es ideal, porque es ideal; y real, porque es real. Mas lo primero que se quiere asentar con esto es que la posición kantiana ofrece evidentemente y sostiene como algo indispensable un aspecto idealista y un aspecto realista. Nadie puede afirmar lo contrario, so pena de falsear claramente los textos de Kant o de torcer tendenciosamente el sentido de sus afirmaciones. La actitud kantiana puede decirse que constituye una tarea de justicia, un dar al César lo que es del César, y a Dios lo que es de Dios: en efecto, Kant sostiene, destaca y llama por su nombre, de un lado, a lo que hay de ideal en el conocimiento, y de otro, a lo que hay de real en él. Es indudable que esta formulación escueta y simplista no es suficiente, ya que según ella apenas habría teoría del conocimiento que no quedara incluida formalmente ahí.

Sin embargo, como decíamos antes, el problema radica en lo que se atribuye a cada aspecto o factor y én cómo se los concibe. Para Kant la "realidad" o "existencia" es sólo exclusivamente eso: no siendo, en efecto, la existencia ningún predicado - si lo fuera, consistiría en una determinación del entendimiento-, ella nò puede ser sino la posición absoluta, lo puesto absolutamente. El único nexo posible con ella lo proporciona el también único instrumento de relación con algo diverso en la gnoseología kantiana: la Empfindung, recepción sensitiva o sensación receptiva, que es el inicio de la percepción (Wahrnehmung) y en general de la experiencia (Erfahrung). ${ }^{8}$ Sin ésta la concepción kantiana no ofrecería abertura ninguna

6 De la primera obra no existe aún traducción al español - ni a ninguna otra lengua-, pero el suscrito trabaja en una a publicarse en los próximos años. De la segunda, la unam reeditó en $196_{4}$ con el $n^{\circ} 62$ de la Colección de la Facultad de Filosofía y Letras la que el Dr. Gaos hizo para Revista de Occidente en 1934.

7 Cf. especialmente sobre el problema realismo-idealismo estos pasajes de la Critica de la razón pura: a) De los paralogismos de la razón pura. El cuarto paralogismo de la idealidad (1 $1^{a}$ ed., 367-405); $b$ ) Los postulados del pensar empírico en general, con la Refutación del idealismo ( $1^{\mathrm{a}}$ ed., $218-235 ; 2^{\mathrm{a}}$ ed., $265_{-287}$ ); $c$ ) El idealismo trascendental como llave para la solución de la dialéctica cosmológica (17 ed., 490-497; $2^{\text {a }}$ ed., 518-525).

8 Cf. para el primer punto: Der einzig mögliche Beweisgrund zu einer Demonstration des Daseins Gottes, 1 Abt., Betracht. 1 u. 2 y Op. Post. $\mathrm{N}^{0} 3761$ y 4396 ; para el segundo 
hacia algo diverso del sujeto conocente y caería en un subjetivismo e idealismo absolutos, sin posibilidad alguna de realismo. Pero con ella se ofrece también sólo eso: nexo, contacto, enlace puro, indeterminado y absolutamente indeterminable, por cuanto toda determinación es trabajo del entendimiento. Con su rigurosa y exclusiva posición realista puede y debe decirse que Kant vio en toda su profundidad el peligro que significa para el conocimiento humano permitir en el realismo-la injerencia de toda otra facultad intelectiva y no intuitiva, y aun imaginativo-constructiva, mediante las cuales podría llegar a "demostrarse" la realidad de cuanto se quisiese. Para él, como se dijo, verdadera y auténtica realidad sólo la puede brindar la experiencia (Erfahrung), la percepción (Wahrnehmung) y la recepción sensitiva (Empfindung), todas ellas elementos de una sola facultad y proceso, que, sensibles a la "vibración entitativa" - llamémosla así- sólo tienen por función activarse ante el "toque", "roce", "frotamiento", en suma, presencia de lo existente, de lo real.

En cierto modo tiene efecto aquí algo contradictorio, es decir, el "conocer" sin conocer; porque estrictamente, en términos kantianos, la "existencia" o la "realidad" (ésta no como categoría, sino como "referencia", "alusión", "indicación") no es conocida ni entendida, sino sólo "conectada", captada, recibida, disponiéndose, para tal "objeto", de las seudocategorías de existente y real, a fin de distinguir sólo y simplemente lo que existe, respecto de la nada. Esa toma de contacto podría interpretarse como un "encuentro entitativo", como la coincidencia espacio-temporal de dos existentes, uno de los cuales "encuentra" y otro "es encontrado". Si, valiéndonos de una imagen, imperfecta sin duda, identificamos el conocimiento con la visión, podemos imaginar al conocente como moviéndose en medio de tinieblas absolutas y "topándose" con otros existentes, de los cuales, por el toparse, sólo "sabría" que "existen".

Kant llama a "esto" - ya diga relación directa con el mundo sensible, ya con el inteligible- del que sólo se "sabe" "eso": cosa en si, objeto trascendental, noúmeno; términos y conceptos sólo relacionales, es decir, usados no por una aplicación directa de verdaderas categorías a sus "objetos", sino por relación a sus opuestos: cosa en nosotros, sujeto trascendental, fenómeno. De manera que lo conocido estrictamente al atribuir tales términos a dichos "objetos", es lo que estos últimos significan y en absoluto algo que procediera de ellos - porque al suponerlos existentes en sí mismos e independientemente del conocer con tales determinaciones, éstas provendrían de ellos por necesidad, a menos que se pensara en una coincidencia entre la facultad conocitiva y la cosa en sí o en una duplicidad innecesaria: ambas cosas absurdas. Aquellos términos, pues, no significan de por sí absolutamente

punto: Critica de la razón pura, $1^{\text {a }}$ ed., pp. 225-6; $2^{\text {a }}$ ed., pp. 272-4, y Op. Post. No $37^{61,}$ 5710,6413 , etc. 
nada conoçido ni conocible: Kant no cesará de repetir, y no hay en toda su obra la más ligera vacilación, que la cosa en sí, el objeto trascendental, los noúmenos son absolutamente in-conocidos $e$ inconocibles; ${ }^{9}$ y si noúmeno se entiende sólo en relación con el mundo suprasensible, inteligible, se admitirá un "conọcimiento práctico", es decir, sólo analógiço, pero jamás teórico.

Dejando aparte el aspecto idealista en la filosofía de Kant - de cuyo sentido, alcance y forma no puede haber simplemente la menor duda-, tal vez podría justificarse la pregunta de si basta, para fundar el aspecto realista, lo que afirma y demuestra en favor del realismo y en contra del idealismo. Son frecuentes y expresos sus razonamientos para apoyar aquél y para refutar éste, especificándolo en las posiciones de Platón, Descartes y Berkeley. Igualmente, sus afirmaciones y argumentaciones sobre la real y verdadera existencia del mundo exterior son constantes y repetidas hasta la saciedad, precisando, naturalmente, que es absurdo e imposible entenderlo o conocerlo como algo en sí, y que sólo lo puede ser como "representación" (Vorstellung) y "aparicion" (Erscheinung), manifestación, fenómeno, etc.

Pero será más objetiva y efectiva sin duda la relación de estas líneas con el pensamiento de Kant, si, al menos, en forma breve, presentamos directamente algunos pasajes suyos, los más ilustrativos sobre el problema que nos ocupa. Voy a reproducir los textos agrupándolos en cuatro puntos: el 1) concierne a la interdependencia de idealismo trascendental y realismo empírico; el 2) a la paralela interdependencia entre las posiciones contrapuestas, a saber, realismo trascendental e idealismo empírico; el 3) :al énfasis puesto sobre el realismo en general de su doctrina, y el 4) al rechazo del idealismo, entendido también en general, que sería como una consecuencia del punto anterior.

1) Parece lo más indicado, pues, ofrecer primeramente en su contexto las dos únicas afirmaciones concretas sobre el nexo entre el idealismo trascendental y el realismo empírico. Helas aquí: "El idealista trascendental puede, por el contrario, ser un realista empirico y con ello; según se le llama, un dualista, es decir, puede conceder la existencia de la materia, sin ir.más allá de la simple autoconciencia, y sin admitir algo más que la certeza de las representaciones en mí y, con ello, el cogito, ergo sum." 10 "En orden a la realidad de los objetos exteriores me es tan poco necesario establecer una deducción, como con vista a la realidad del objeto de mi sentido interno (mis pensamientos), pues ellos son por ambos lados no otra cosa que representaciones, cuya percepción inmediata (conciencia) es al mismo tiempo una prueba suficiente de su realidad [/]. Así pues, el idealista trascendental es

9 Cf. passim el primero de los pasajes aludidos en la nota 7 .

10 Critica de la razón pura, $1^{\text {a }}$ ed., p. 370 . La referencia de edición y página remite a las ediciones originales $\left(1^{a}, 1781 ; 2^{a}, 1787\right)$ en alemán. Todas las traducciones de Kant y de Fichte aqui empleadas son mias. En general los subrayados especificos son también míos. 
ún realista empirico y le concede a la materia, como fenómeno, una realidad, que no puede ser deducida, sino que es percibida inmediatamente." 11 En este segundo pașaje atiéndase, además, a la afirmación repetida de la no-deducción de la realidad o existencia, sea porque no es necesaria, sea porque no es posible.

2) En seguida parece oportuno considerar los asertos de Kant sobre la también estrecha relación entre las posiciones del par contrario, es decir, entre el realismo trascendental y el idealismo empirico, donde el filósofo no procede tanto a mostrar la falsedad del primero, cuanto a señalar, sobre todo, la necesidad que tiene éste de recurrir al segundo para resolver los problemas que le plantea su propia concepción errónea. En la primera referencia (las dos que citamos pertenecen a un mismo pasaje extenso, dedicado especialmente al tema) ${ }^{12}$ Kant explica antes en qué consiste aquel primero: "A este idealismo [trascendental] se contrapone un realismo trascendental, que considera tiempo y espacio como algo dado en sí (independientemente de nuestra sensibilidad). El realismo trascendental, por tanto, se representa los fenómenos exteriores (si se concede su realidad) como cosas en sí mismas, que existen independientemente de nosotros y de nuestra sensibilidad, y que, por tanto, también conforme a los conceptos puros del entendimiento estarían fuera de nosotros. Este realista trascendental es propiamente quien la hace luego de idealista empirico y quien, después de haber supuesto falsamente sobre los objetos de los sentidos, que, si deben ser exteriores, habrian de tener su existencia en sí mismos también sin los sentidos, descubre en este punto de vista que todas nuestras representaciones de los sentidos son insuficientes para hacer cierta la realidad de las mismas." 13 En la segunda referencia opone Kant, además, su propia tesis idealista al llamado idealismo empírico: "Por el contrario, el realismo trascendental cae en perplejidad y se ve precisado a dejar sitio al idealismo empirico, porque considera los objetos de los sentidos externos como algo diverso de los sentidos mismos, y las simples representaciones como seres subsistentes, que se encuentran fuera de nosotros; porque indudablemente, dentro de la mejor conciencia de nuestra representación de esas cosas, está aún muy lejos de ser cierto que, si existe la representación, también existe el objeto correspondiente a ella; por el contrario, en nuestro sistema estas cosas exteriores, a saber, la materia, en todas sus figuras y modificaciones, no son nada más que meros fenómenos, es decir, representaciones en nosotros, de cuya realidad nos hacemos inmediatamente conscientes." 14

3) Como, sin duda, el aspecto general idealista del pensamiento kantiano

11 Ibid., p. 371 .

12 Me refiero al primer párrafo de los indicados en la nota 7 .

13 Crítica de la razón pura, $1^{\text {a }}$ ed., p. 369.

14 Ibid., pp. $37^{1-2 .}$ 
era mucho más notorio que el realista, parece natural y requerido el énfasis explícito que puso Kant sobre el realismo de su posición, aclarando ciertamente su sentido y alcance, a fin de que se entendiera correctamente su doctrina, resguardándola de interpretaciones falsas. La insistencia sobre el realismo puede decirse que aparece a lo largo de la Critica de la razón pura, siempre que se plantea el problema que nos ocupa. He aquí uno de los pasajes más conspicuos: "Nuestro idealismo trascendental, por el contrario [es decir, frente al realismo trascendental y al idealismo empírico], admite que los objetos de la intuición externa, exactamente como son intuidos en el espacio, también son reales, y todas las modificaciones en el tiempo, son así como el sentido interno las representa. Pues, como el espacio es ya una forma de aquella intuición, que nosotros llamamos externa, y sin objetos en el mismo no se daría absolutamente ninguna representación empírica: así podemos y tenemos nosotros que aceptar ahi' seres extensos como reales, e igualmente sucede también con el tiempo. [...] En el espacio, empero, y en el tiempo la verdad empirica de los fenómenos está suficientemente asegurada y diferenciada bastante del parentesco con el sueño, si en una experiencia se conectan ambos conforme a leyes empíricas correcta y generalmente." is En otro se añade una ligera aclaración, de acuerdo con el idealismo trascendental: "Toda percepción externa, por tanto, demuestra inmediatamente algo real en el espacio, o es más bien lo real mismo, y según eso, en consecuencia, el realismo empirico está fuera de duda, es decir, a nuestras intuiciones externas corresponde algo real en el espacio. Indudablemente, el espacio mismo, con todas sus manifestaciones, en cuanto representación, está sólo en mí; pero en ese espacio, sin embargo, está igualmente dado lo real, o el material de todos los objetos de la intuición externa, real e independientemente de toda ficción [...]" ${ }^{16}$ Un tercero resulta de especial interés por hacer hincapié sobre la imposibilidad del realismo en general, si no se presupone el idealismo trascendental o "crítico": "Mi llamado idealismo (propiamente crítico) es por tanto de una especie muy particular, a saber, de tal clase que trastorna al ordinario; que todo conocimiento a priori, aun el de la geometría, sólo por su medio recibe realidad objetiva, la cual, sin esta mi demostrada idealidad del espacio y del tiempo, no podría afirmarse en absoluto aun por los realistas más fervientés." 17

4) Para quienes advirtieron de inmediato el carácter idealista general de las doctrinas de Kant, debe de haber parecido un tanto extraño, a primera vista, que un párrafo de la Crítica de la razón pura - breve sin duda y como subdivisión de otro- ostentase el título de "Refutación del idea-

15 Ibid., pp. $49^{1-2}$.

16 Ibid., p. 375 .

17 Prolegomena, p. 375 (la referencia de página remite a la $1^{\text {a }}$ edición original alemana de 1783 ). 
lismo" y que "El cuarto paralogismo" de la razón pura fuese el "de la idealidad ( de la relación externa)". ${ }^{18}$ Pero, sin duda, Kant sabía en qué aspecto y sentido era y debía ser idealista su gnoseología, y en qué aspecto y sentido debía ser realista. Por ello, siempre que es necesario, rechaza el falso idealismo, distinguiéndolo del verdadero, y sostiene el único realismo posible, precisando en qué esfera debe quedar situado. Y no sería ininteresante señalar que los textos más explícitos en que Kant opone las tesis del idealismo puro a las suyas propias, que más bien suenan a realismo, proceden de los Prolegomena, cuya tarea en gran parte fue aclarar aspectos de la Crítica ( a $^{\text {a }}$ ed.). Veamos, pues, primero, cómo opone los dos idealismos, es decir, el "genuino" (absoluto, específico, radical) y el suyo propio: "El principio de todos los idealistas genuinos, desde la escuela eleática hasta el obispo Berkeley, está contenido en esta fórmula: 'Todo conocimiento por medio de los sentidos y la experiencia no es sino mera apariencia, y sólo en las ideas del entendimiento puro y de la razón hay verdad.' [/] El principio fundamental, que rige y determina universalmente mi idealismo, es por el contrario: 'Todo conocimiento de cosas por el mero entendimiento puro o la razón pura no es sino mera apariencia, y sólo en la experiencia hay verdad.' [/] Pero esto es exactamente lo contrario de aquel idealismo genuino; ¿cómo puedo, entonces, servirme de ese término para un propósito totalmente contrapuesto [...]?' 19 En el siguiente pasaje se destaca con más nitidez, cómo el idealismo falso consiste en atribuir idealidad a algo cuya realidad debe precisamente mostrarse: "El idealismo consiste en la afirmación de que no se dan otros seres que los pensantes; las demás cosas, que nosotros creemos percibir en la intuición, serían sólo representaciones en los seres pensantes, a las cuales de hecho no correspondería ningún objeto que se encontrara fuera de éstas. Yo digo, por el contrario: están dadas a nosotros, como objetos de nuestros sentidos, cosas que se encuentran fuera de nosotros; únicamente no sabemos nada de lo que puedan ser en sí mismas, sino que conocemos sólo sus manifestaciones, es decir, las representaciones que producen en nosotros, al afectar nuestros sentidos." 20 En fin, en la continuación del texto anterior, después de presentar lo esencial de su doctrina positiva sobre la realidad del mundo exterior, afirma que aquélla es contraria al idealismo: "Conforme a esto, concedo yo ciertamente que fuera de nosotros se dan cuerpos, es decir, cosas que, aun cuando según lo que puedan ser en sí mismas nos son completamente desconocidas, nosotros las conocemos mediante las representaciones, que nos produce su influjo sobre nuestra sensibilidad, $y$ a las que damos la denominación de un cuerpo, la cual palabra, por tanto, significa simplemente la manifestación de aquel objeto

18 Critica de la razón pura, 2a, p. 274; y 1a, p. $3^{66}$.

19 Prolegomena, p. 374.

20 Idem, pp. 288-9. 
desconocido para nosotros, pero no por ello menos real. ¿Se puede acaso llamar a esto idealismo? Sin duda, es precisamente lo contrario de ello." 21

No debe ocultarse - y no se me oculta - que sobre la negación del conocimiento de una realidad en sí y sobre la afirmación del conocimiento de una realidad sólo fenoménica es sobre las que se apoyan las objeciones contra el realismo kantiano y de la filosofía trascendental, así como las atribuciones a uno y otra de idealismo. Sin embargo, como dice Kant en diversos lugares, si el mundo exterior - mundo empírico y de los sentidoses algo en si, es decir, es en sí como aparece y contiene de por sí las determinaciones que manifiesta, independientemente del conocimiento, entonces resulta imposible ponerse en contacto o establecer enlace con él, porque el conocimiento humano no dispone de facultad o instrumento intuitivo-intelectivo que pueda, por decirlo así, pasando a través de lo que aparece, o prescindiendo de ello y olvidándolo, llegar a lo que sólo es.

$\mathrm{Si}$, por el contrario, se recurre a la facultad deductiva del entendimiento y de la razón, entonces quiere decir que se utiliza un medio, que hay un intermediario, el cual por esencia y definición no posee, ni puede en consecuencia comunicar, la modalidad que se pretende, es decir, la existencia real: en otras palabras, se tratará entonces de una mera conclusión o deducción, cuyos conceptos, proceso y estructura pertenecen a otro nivel y tienen otra modalidad que la existencia real. Pero, sobre todo, el mundo exterior, o más bien la exterioridad del mundo, en cuanto tal (y aun la "interioridad" empírica del Yo, del alma, aparecida al sentido interno) tiene que ser, por principio, algo que aparece, que se manifiesta, que precisamente se "exterioriza" y sólo puede ser captada o percibida por un instrumento adecuado a ello, a saber, los llamados "sentidos externos" o "internos". Con éstos no se puede "inteligir" ni conocer forma alguna ni esencia entitativa, más allá de todo fenóméno o aparición, sino solamente estos últimos.

Según esto, por tanto, la adecuación o correspondencia entre el mundo exterior, como objeto, y los sentidos externos, como sujeto, determinan, por un lado, la necesidad de aparición del mundo exterior y la imposibilidad de aparición del mundo en sí; y por otro, la imposibilidad de captación de éste por ựa facultad intuitivo-intelectiva y la necesidad de percibirlo mediante los sentidos, es decir, la experiencia, la empirie. Brevemente: el mundo exterior tiene que aparecer y no puede quedarse sólo en sí: pues por esto lo entenderíamos, mientras que por lo primero "sabríamos" que existe.

Ahora bien, epuede hablarse, dentro del conocimiento, de una realidad del mundo exterior diversa de la fenoménica? Esa otra realidad del mismo sería, como dice Kant, la trascendental, es decir, "realizada" en estructuras ontológicas; de donde resultaría, como aludí antes, que lo fenoménico se 
convierte en entitativo, lo empírico en trascendental, lo sensible en inteligible, los "accidentes" en esencias y formas. Pero tal realidad, insistimos, no podría ser captada inmediatamente; no sería posible establecer un nexo directo del conocente con ella, sino sólo indirecto, a través de un medio estructural o abstraído, lo que significaría renunciar a ella: pues valerse de un medio equivale únicamente a entenderla, pensarla, concebirla, es decir; en última instancia, admitirla sólo como deducida, lógica, ideal.

Asi pues, la única realidad posible del mundo exterior, base, según Kant, de todo realismo, es la fenoménica y empírica; y la facultad sensible es, también, la única capaz de ponerse en contacto inmediato con ella. Atribuir al mựndo exterior una realidad metaempírica -más allá de la experiencia y del fenómeno- es abusar de conceptos y categorías o hundirse en lo indeterminable e inconocible. Toda filosofia que sostenga el primer punto de vista, será realismo verdadero y objetivo; la que afirme el segundo, vendrá a ser un realismo pretensioso e infundado.

\section{V}

La gnoseología fichteana, como toda su filosofía, no es sino un desarrollo, perfeccionamiento y consumación de las doctrinas de Kant, según puede comprobarse tanto expresa como implícitamente, es decir, ora en las innumerables afirmaciones de Fichte, ora en las tesis mismas, el método y los razonamientos ofrecidos en sus obras - quedando aparte el problema de la rectitud y justificación de dicho perfeccionamiento, el cual se basa en un supuesto y sigue una dirección determinados, que tal vez no fueran los que Kant mismo pensó o los exigidos por la doctrina. ${ }^{22}$ Todo desarrollo fichteano de temas gnoseológicos muestra referencias directas a Kant y a puntos concretos de su teoría del conocimiento, así como un manejo continuo de sus conceptos y terminología, destacándose una aceptación y concordancia fundamentales con aquélla, según puede advertirse sobre todo en las obras citadas: Lógica trascendental y Primera y Segunda Introducción a la doctrina de la ciencia.

La labor de Fichte podría, más concretamente, formularse en estos dos puntos: a) por lo que se refiere a la base, es decir, a los principios y puntos de partida, se ocupa en buscar y demostrar para el conocimiento humano una razón última y un fundamento unitario en orden al sistema perfecto, señalando la primera, dentro del ámbito de la razón práctica, en el deber ser de la realización del Yo formalmente necesaria, y el segundo en la unidad

22 El suscrito presentó como tesis doctoral en 1966 en la Universidad de Munich un estudio sobre el tema, titulado: Der vollständige transzendentale Idealismus, que reelaborado en castellano aparecerá en la Colección de Diánoia con el nombre: El desarrollo fichteano del idealismo trascendental de Kant. 
originaria del Yo, que en acto primero y absoluto se pone a sí mismo (fundamento que Fichte considera implícito e iniciado en la unidad trascendental de la apercepción de Kant); $b$ ) por lo que se refiere al proceso mismo, a las etapas de desarrollo intermedio y a los extremos, se dedica a rectificar, precisar, completar, perfeccionar y hacer explícitos aspectos particulares de método y de doctrina, en general secundarios, aunque a veces de relativa importancia.

Sobre el problema que nos ocupa, la aceptación por Fichte de la teoría de Kant no sólo es manifiesta, sino que puede decirse que aquél insiste tal vez más que éste sobre el punto, es decir, sobre la interdependencia entre el idealismo trascendental y el realismo empirico - si bien debe observarse que Fichte nunca habla en forma expresa ni terminológica de la paralela correlación entre realismo trascendental e idealismo empírico, y apenas se podría descubrir en algún desarrollo una alusión indirecta al tema. Además, dentro de mis conocimientos, Fichte no sólo no habla de esa correlación, sino que tampoco menciona en parte alguna un "idealismo empírico", por más que recuerda el pasaje de la Critica de la razón pura, donde Kant se ocupa del idealismo de Berkeley y del de Descartes; ${ }^{23}$ para referirse a todo idealismo que no sea el trascendental, Fichte se sirve del término dogmático. De manera semejante, este filósofo no denomina jamás trascendental al realismo, sino que para referirse a la posición falsa de éste, lo llama también dogmático y a veces trascendente.

En el desarrollo que Fichte hace del problema pueden destacarse los siguientes aspectos: a) empleo reiterado de las fórmulas kantianas y aceptación explícita de su tesis; b) explicación y comentario de algunos elementos de la doctrina de Kant al respecto; $c$ ) exposición de aquello en que consiste para él el idealismo trascendental, por un lado, y su necesaria complementación, el realismo empírico, por otro; $d$ ) sostenimiento de una teoría ulterior, conforme con la orientación y el sentido de toda su filosofía, sobre la unión e identificación de las dos posiciones.

a) Sobre el primer punto leamos ante todo, entre otras varias, estas netas declaraciones: "El idealismo trascendental de Kant es al mismo tiempo realismo empírico..." 24 "Aquí se halla el realismo empirico kantiano, que sin embargo es un idealismo trascendental." 25 "Esto quiso decir Kant, o por lo menos debió quererlo, cuando dijo: que su sistema era un realismo empirico, pero un idealismo trascendental..." 26 "Desde este ángulo la doc-

23 Sämtliche Werke, tomo I, p. 21. Se trata de la primera edición de las Obras Completas hecha por I. H. Fichte, hijo del filósofo, en Bonn, 1834, los tres últimos tomos (IX-XI), y en Berlín, $1845^{-6}$, los ocho primeros (I-VIII). En lo que sigue se citará $S W$ y los tomos del I al XI.

24 SW IX, 59.

$25 S W$ I, 490 .

$26 S W I X, 364$. 
trina es realismo empírico... Sin embargo... de este modo, el idealismo es trascendental." 27 La aceptación de la doctrina kantiana está clara, aunque en general no expresá, en todos los pasajes donde Fichte se ocupa de nuestro problema, muchos de los cuales leeremos en lo que sigue. Como muestra de una afirmación explícita veamos ésta: "... nosotros podemos apropiarnos esta expresión [realismo empírico - idealismo trascendental], explicada por cierto. La doctrina de la ciencia [denominación que da Fichte a su filosofía] es realismo empirico... y es idealismo trascendental..." 28

b) Como explicación y comentario de diversos. puntos de la tesis kantiana sobre idealismo y realismo, pueden tomarse en general las exposiciones de Fichte sobre sus propios puntos de;vista al respecto, si atendemos a la amplia y fundamental coincidencia entre su gnoseologia y la de Kant. Lo anterior es tan cierto, sobre todo cuando la coincidencia es mayor, que se necesita un análisis muy sutil y profundo para distinguir lo que Fichte toma de Kant y lo aportado por él mismo: distinción que no es facilitada, como podría suponerse, por el uso de una terminología propia, sino, al contrario, hecha más difícil, pues se tiene que examinar si a ella corresponde en realidad una doctrina nueva o un contenido ya propio. Sin embargo, puede ilustrarse este punto con un pasaje en que, como un estadio intermedio, Fitche parte de conceptos básicos de Kant (cosa en si, empirie) y explica el proceso de su teoría idealista-realista: Ella "concede y demuestra que, cuando el entendimiento habla de una cosa en si, tiene que hablar de esa manera, y tiene en ello todo el derecho; que, sin embargo, este en-si sólo es en cierto respecto y quedando oculto su principio, pero no es un en-sí verdadero y subsistente. Esta visión se logra mediante trascendentalidad, que es precisamente elevación sobre la empirie hacia la intuición de la ley y de la vida del espíritu. En la empirie está dada una cosa en si; sobre ello no hay duda alguna. Pero es una cuestión muy diversa, qué validez debe tener la empirie misma y si ella es el saber absoluto. Pues si llegara a descubrirse que sucede en otra forma, quedaría también degradada con ella la cosa en si"'.29

c) Entre el aspecto anterior y el presente puede decirse que sólo hay una diferencia de grado, es decir, del grado de aproximación o alejamiento de Fichte con respecto a Kant: ello determinaría si aún es sólo comentario o se trata ya de formulación, método y pensamiento propios. Esto mismo último debe entenderse dentro de la afirmación general de la coincidencia del punto de vista fichteano con el de Kant: es decir, propio significará aquí, naturalmente, no una doctrina del todo diversa o extraña, sino ún desarrollo ulterior, una complementación, explicitación, nueva perspectiva y profundización de las bases o puntos de partida. A través de las diversas expo 
siciones de sus puntos de vista, advertiremos, pues, cómo Fichte ve la teoría kantiana. y la transforma y re-crea.

El punto central para Fichte en orden a la explicación del problema entre idealismo y realismo - ambos sin duda verdaderos en su propio nivelconsiste primeramente en distinguir lo que sostiene, y puede sostener, cada uno, así como en señalar el carácter y resultado u objeto de sus afirmaciones. He aquí el principio de una argumentación que establece el filósofo para explicar la diferencia. entre las dos posiciones: "Los adversarios no entienden al idealismo en esto, no se lo conceden, y sólo quieren convertirlo en una certeza con mucho inferior. ¿Dónde se halla el malentendido? Aquí: ellos creen que nosotros negamos o dudamos del es categórico: la estufa es. Sin embargo, nosotros no negamos esto en absoluto, sino que lo fundamos más firmemente que lo que aquéllos son capaces. Ellos se quedan en la impotente afirmación: tal cosa es, y con eso basta, yo ciertamente lo sé; pero no pueden elevarse a un enlace de este es con un fundamento, y por cierto con un fundamento verdadero y permanente [...]" 30 . Según esta primera distinción, lo característico del realismo es la simple categoricidad, es decir, el carácter puramente positivo y fáctico de sus afirmaciones, mientras el idealismo tiene como tarea buscar una fundamentación de ese carácter en algo enteramente diverso y superior. ¿Cuál es ello? "Nosotros tenemos [prosigue Fichte], además de aquella intuición del ser, del es categórico, aun también un concepto del ser, del verdadero y real, que ciertamente es determinado a su vez en una forma múltiple. Este ser real, pues, lo negamos con derecho al fenómeno empírico. Éste es, decís vosotros; naturalmente, prọeguimos nosotros, sólo qué no el ser, sino su mera imagen." 31 "A través de los términos "intuición" y "concepto" podemos advertir su relación con Kant y ver cómo lo que Fichte llama "ser", es el objeto constituido por el entendimiento, y la "imagen", del ser, es la aparición, el fenómeno. Reafirmando su posición básica, concluye el filósofo: "La doctrina de la ciencia es realismo empirico, pues concede absolutamente el es categórico. [ [ $\mathrm{Y}$ es] idealismo trascendental: pues se eleva por encima de la experiencia hasta un concepto puro del ser, y si ceñimos la experiencia a éste, la encontramos no como ser, sino como imagen." 32

Con términos más fichteanos se establece en otro pasaje la fundamentación que el entendimiento o la facultad intelectiva, como algo "absoluto", hace de lo dado o manifestado a ella, destacando también la dependencia sobre todo de esto respecto de aquélla: "Nosotros presuponemos como lo absoluto el ver, saber, ojo, que mira y no puede dejar de mirar. De aqui, entonces, resulta el ser, el mundo -en el ojo, a saber, como visto. Así tene- 
mos una unión y un principio del nexo. Esto es, pues; idealismo incondicionado. - Ahora bien, a este ojo se le ofrece ciertamente un mundo, por tanto, un ser en si y, en esta forma, no como producto de un ver. Desde este ángulo la doctrina es realismo empírico: así el ojo mira, porque es un ojo intelectivo (intuición que se entiende como imagen), no mero esbozo de una imagen. Que, sin embargo, es su producto, se ve sólo subiendo más alto; así el idealismo es trascendental. [/] Mi propósito principal era fijar este punto correctamente, y proteger a ustedes de un idealismo vacío [...], que suprime, más que al [¿idealismo?] trascendental, al realismo empírico." 33 Otra formulación de la dependencia realismo-idealismo, más fichteana todavía, mediante conceptos y procesos que van más allá de Kant —l "sentimiento" (Gefühl) y la limitación (Beschränkung)-, la remata Fichte declarando su conexión con Kant: "Mas el Yo empirico, considerado desde el punto de vista trascendental, se explica sin duda su propio 'sentimiento'; conforme a la ley: nada limitado sin algo limitante; él se crea por medio de la intuición una materia extensa, sobre la cual traslada, como sobre su fundamento, aquello meramente subjetivo del 'sentimiento', y sólo por medio de esta síntesis hace para sí un objeto. El análisis continuado y el continuado explicar de su propio estado le da a él su sistema del mundo; y la contemplación de las leyes de ese explicar le da al filósofo su ciencia. Aquí se halla el realismo empirico kantiano, el que sin embargo es un idealismo trascendental." $34 \mathrm{Y}$ adelantándose a una posible, aunque ciertamente muy improbable, interpretación exagerada del realismo que atribuye él a su "doctrina de la ciencia", explica en qué sentido debe algo considerarse como dependiente, por una parte, o independiente, por otra, de la facultad conocitiva: "Mas a despecho de su realismo, esta ciencia no es trascendente, sino que en sus más intimas profundidades sigue siendo trascendental. Ella explica, en efecto, toda conciencia por algo que existe independientemente de toda conciencia; pero no olvida que en esta explicación se rige también conforme a sus propias leyes, y tan pronto como reflexiona sobre esto, aquello-independiente, a su vez, viene a ser un producto de su propia facultad intelectiva, con ello algo dependiente del Yo, en cuanto que debe existir para el Yo (en el concepto de él)"'.35

Veamos ahora en particular la presentación del carácter o aspecto realista, que hace Fichte de su posición ante el problema. Puede decirse que como Kant, o sin duda aun mucho más que éste (el idealismo de aquél ha sido considerado siempre - y con razón - como más avanzado que el kantiano y tal vez el más avanzado de todos, ya que se lo ha designado con el título de absoluto y subjetivo), Fichte necesita destacar e insistir en la parte

33 Id., 100

$34 S W$ I, 490 .

35 Id., 280. 
y fundamento de realismo que tiene su doctrina o él le atribuye. Parece natural que el realista no haga hincapié particularmente sobre su realismo, y por igual el idealista sobre su idealismo, tal vez como consecuencia de su actitud dogmática o ingenua, pero sobre todo por no considerarlo necesario. Kant y Fichte destacan el realismo de su posición, tanto por su actitud critica fundamental, como por la apariencia de "irrealismo" de su doctrina y por la necesidad de sostener' y fundamentar lo que de realismo e idealismo debe tener por igual el conocimiento, respondiendo así a todas las objeciones reales o posibles de sus adversarios; pero también ambos se preocupan siempre por precisar exactamente cómo ha de entenderse su realismo frente a cualquier interpretación trascendentista y dogmática, la cual vendría a echar por tierra el propósito fundamental de toda su filosofía.

Las afirmaciones realistas de Fichte son a veces tan enérgicas, que parecen a veces llegar a lo excesivo y paradójico. Como Kant, él atribuye a su idealismo, por ejemplo, ser el factor del verdadero realismo, de manera que la negación de éste implicaría la absoluta negación de todo: "Por esto, la filosofía trascendental [dice el filósofo], que también puede llamarse idealismo trascendental, es al mismo tiempo un realismo, y a la vez el más fuerte $y$ decidido, que puede darse. Si se pregunta: ¿No existe, pues, ningún mundo? ¿No están, pues, las cosas en el espacio? ¿No caen los fenómenos del mismo en el tiempo?, sirve como respuesta: Ciertamente es así, y no sucede de otra manera, pues de lo contrario tendría uno que deshacerse de la razón, de la vida, de la inteligencia; pero entonces no se daría absolutamente nada. Por tanto, nuestras representaciones contienen verdad, verdad objetiva, fuera de la cual no se da ninguna. Nuestras representaciones concuerdan con las cosas, pues ambas son lo mismo." 36 En otro texto el realismo es explicado como la dependencia empírica con respecto a algo independiente, simplemente presente, cuyas determinaciones empero provendrán de la facultad conocitiva: "Según esto, la doctrina de la ciencia es realista. Ella muestra que la conciencia de las naturalezas finitas no puede absolutamente explicarse, si no se admite la presencia de una fuerza, independiente de las mismas y contrapuesta del todo a ellas, de la cual ellas mismas según su existencia empirica son precisamente dependientes. Pero tampoco afirma otra cosa que tal fuerza contrapuesta, la cual es simplemente sentida por el ser finito, pero no conocida. Todas las determinaciones posibles de esta fuerza o de este no-Yo, que pueden presentarse hasta el infinito en nuestra conciencia, se compromete ella a deducirlas de la facultad determinante del Yo, y tan cierto como ella es doctrina de la ciencia, tiene que poder deducirlas." 37 El mismo aspecto de la existencia independiente del mundo es formulado en otro pasaje casi en los términos de un realismo trascendente,

36 Nachgelassene Schriften, Hrsg. von Hans Jacob. Berlín, 1938, tomo 2, p. 48. $37 S W 1,279-80$. 
si bien se añaden precisiones para evitar esa interpretación: "El fundamento de todo ser real (del mundo de los fenómenos) ha sido expuesto en la forma más profunda y exhaustiva, en parte según su carácter formal, en parte según el material. El primero consiste en que el mundo debe ser independientemente de todo saber, que ahi en el saber mismo sea reconocido como saber; en que el mundo sería, aun cuando no existiera el saber de él; además, en que, con todo, no debe ser necesariamente, sino que por igual también podría no ser. Especialmente tenemos que habérnosla con el primero; y se equivoca uno mucho si piensa que el idealismo trascendental niega la realidad empirica del mundo de los sentidos, y cosas semejantes: él simplemente demuestra en ella las formas del saber, y las aniquila por lo mismo como algo subsistente por sí y absoluto." 38

Otro carácter que Fichte destaca en la presentación de su realismo, es la necesidad o necesariedad de éste, dentro de la finitud del ser humano, que ha de realizarse, es decir, que debe obrar y para ello conocer, si es que quiere existir como tal. Una reflexión del filósofo se desarrolla en torno al origen de la representación de la materia y llega a oponer, y preferir, el realismo al idealismo en un determinado sentido: "Es necesario [dice Fichte] que la razón finita se figure un mundo material; pues mediante unión de algo contradictorio se nos origina el concepto de materia, como muestra la doctrina de la ciencia. Debe concebirse algo en conflicto, y por cierto mediante la facultad imaginativa. El resultado de la unión es materia. La filosofía crítica es, por tanto, realismo y en este sentido no idealismo. Aquí el realismo es algo así que niega que la cosa en si sea algo, y el idealismo afirma: es algo. Sólo que la filosofía crítica no es un dogmatismo, porque no sostiene nada de la cosa en sí. El idealismo es también un verdadero sistema metafísico, pues se eleva sobre aquél y explica la legitimidad del mundo material." 39 Otra reflexión enlaza aquella necesidad - “imposición"- - con la actividad - "obrar" - del ser humano: "El realismo, que se impone a todos nosotros y aun al más decidido idealista cuando se llega al obrar -es decir, la suposición de que existen objetos del todo independientes de nosotros y fuera de nosotros-, se halla en el idealismo mismo, y en él es explicado y deducido; y la deducción de una verdad objetiva, así en el mundo de los fenómenos, como también en el mundo inteligible, es por cierto el único propósito de toda filosofía." 40

d) El final del pasaje correspondiente a la nota 36: "Nuestras representaciones concuerdan con las cosas, pues ambas son lo mismo", y la "inherencia" del realismo en el idealismo, expresada en el texto anterior, pueden servirnos como un primer indicio de la unión y hasta identificación que,

38 SW II, 104-5.

39 NS 2, 49.

$40 S W$ I, 455 , nota. 
según Fichte, se da y debe mostrarse entre realismo e idealismo. Kant, según dijimos, no sostiene ni se refiere expresamente a ello, mas puede decirse que al menos en parte y como fundamento se halla dicha tesis en sus afirmaciones, ya que si el idealismo trascendental "es al mismo tiempo" un realismo empírico, se supone que son sólo como dos aspectos, funciones, vertientes, ètc., de una misma realidad, o más bien, del proceso que es el conocimiento mismo; por tanto, en cierta forma Fichte saca sólo la conclusión de las premisas puestas por Kant. Esta identificación de realismo e idealismo, señalada expresamente y demostrada -o más bien, deducidapor Fichte, partiendo de bases suficientes y muy evolucionadas de Kant, es un aspecto o parte del propósito fundamental de aquél, de encontrar por un lado la unidad absoluta originaria de ser y conocer, y por otro, la unidad profunda y última entre las dos facultades fundamentales del conocer: la sensibilidad y el entendimiento. Todo ello, como indiqué antes, no es sino la tarea y preocupación centrales de la filosofía fichteana.

Empleando términos propisimos y el peculiar lenguaje de su filosofía, Fichte establece con toda claridad, primero, las bases del problema, refiriéndose a las posiciones dogmáticas, que luego, al situarlas en su verdadero plano -el del obrar, de la actividad- perderán ese carácter y resultarán aptas para reducirse a una posición intermedia, que vendrá a ser la unión misma de ambas: "El resultado de la primera forma de reflexionar, funda un idealismo dogmático: toda realidad del no-Yo es exclusivamente una trasladada del Yo. El resultado de la segunda forma de reflexionar, funda un realismo dogmático: no puede ser trasladada, si no está ya presupuesta una realidad independiente del no-Yo, una cosa en si. La sintesis que debe ahora establecerse, según esto, tiene sobre sí nada menos que la tarea de resolver la disputa y mostrar el camino intermedio entre idealismo y realismo. [/] Ambas proposiciones deben unirse sintéticamente, es decir, deben considerarse como una y la misma [proposición]. [...] Según esto, el sentido más profundo de la síntesis anterior es el siguiente: fundamento-ideal y real son una y la misma cosa en el concepto de la efectividad (y con ello, en todas partes, pues sólo en el concepto de la efectividad se presenta un fundamento-real). Esta proposición, que funda el idealismo crítico, y que mediante éste une al idealismo y al realismo, no quiere entrarle a los hombres; y que no les quiera entrar, depende de la falta de abstracción".41 Como remate de esta exposición del pensamiento de Fichte sobre el problema realismo-idealismo y de su aportación personal para resolverlo, puede servir este último pasaje, donde explica el filósofo cuál es el trasfondo último del problema, explicación que apunta al reconocimiento de una aporía — "círculo" - y donde, sin embargo, propone una solución para ésta, acuñando dos términos valiosos, aunque sin duda esencialmente paradójicos: "Esto [declara Fich- 
te]: que el espíritu finito ha de poner necesariamente algo absoluto fuera de él (una cosa en sí) y sin embargo, por el otro lado, ha de reconocer que eso mismo sólo existe para él (que es un noúmeno necesario), es aquel círculo que él puede extender hasta el infinito, pero del cual no puede salir jamás. Un sistema que absolutamente no tome en consideración ese círculo, es un idealismo dogmático, pues propiamente sólo es el círculo señalado, que nos limita y nos convierte en seres finitos; un sistema que se figure haber salido de aquél, es un dogmatismo idealista trascendente. [/] Entre ambos sistemas la doctrina de la ciencia sostiene positivamente el medio, y es un idealismo critico, al que también se podría llamar un real-idealismo, o un ideal-realismo." 42

\section{VI}

De acuerdo con las sumarias y sencillas reflexiones anteriores, pero sobre todo con base en los razonamientos citados de la filosofía trascendental, puede considerarse como establecida la necesidad de la presencia conjunta y complementaria de realismo e idealismo en el conocimiento, es decir, de elementos o factores de carácter tanto ideal como real, restringiéndolos por cierto a lo significado por los términos: real como la mera presencia entitativa, el simple estar-ahi existencial de algo - "cosa en si"-, absolutamente indeterminado e indeterminable en si y por si y, según ello, inconocido e inconocible, lo cual sin embargo no puede en absoluto ser aportado por la facultad conocitiva, so pena de reducir el conocimiento a una mera ficción y especulación o a la creación entitativa; ideal como la configuración y estructuración o constitución de aquel algo informe, mediante "campos" coordinativos y estructuras, es decir, formas, esquemas, conceptos o categorías e ideas, todo lo cual no puede ser aportado por la "realidad", a menos que se degrade el conocimiento a simple reflejo o reproducción de aquélla.

Independientemente de la concepción concreta y en detalle de factores o elementos, funciones y procesos, puede, pues, considerarse como constituida y demostrada la dualidad, o mejor aún alteridad, antes dicha. El problema efectivo que nos queda, como dijimos, es la atribución desmedida, es decir, infundada e inespecífica, de los resultados o efectos de un factor al opuesto, y viceversa: esto es, atribuir al conocimiento la ficción, deducción o creación entitativa de la realidad; o asignar a ésta, como agente externo y primario -el secundario e interno sería la mente misma- la configuración y estructuración -aun en un sentido objetivo y pasivo, derivado de otro subjetivo y activo, ajeno al ser humano-, propias del conocimiento.

Ahora bien, parece obvia, a primera vista, e irrefutable la posición contraria, a saber: atribuir la "realidad" a algo diverso e independiente, como existencial o entitativo, del sujeto conocente; y asignar la conformación y

42 Id., 281. 
estructuración a la facultad conocitiva. Lo primero, porque, de no ser así, toda realidad se desvanecería y aun el concepto mismo carecería absolutamente de significado, confundiéndose con cualquiera de sus contrarios en los diversos planos; lo segundo, porque, de no ser así, desaparecería el verdadero y legítimo sentido, único posible, del acto o de la operación conocitiva en cuánto tal, así como de los elementos, funciones y procesos en que, según análisis autoconsciente, ella consiste.

Sin embargo, aun después de las afirmaciones y argumentos más conspicuos, de Kant sobre todo y también de Fichte, aquí citados, parece inevitable tener que admitir que aún falta algo para la demostración absoluta y definitiva; que todavía queda aquí, como diría N. Hartmann, un resto problemático, no resuelto y tal vez insoluble, que constituya precisamente una aporía, la cual revele el último carácter aporético de la reflexión filosófica y del conocimiento humano.

La complementación o integración, pero sobre todo la asimilación e identificación de los dos aspectos o elementos en el conocer, es la que hace, a mi juicio, que el descubrimiento de la verdadera y justa aportación de cada uno, buscada ora analítica ora deductivamente, sea tan difícil, quizá imposible. Porque, precisamente esa asimilación y compenetración, es decir, la interacción de uno sobre otro, no permitiría descubrir en forma absoluta, a menos que se poseyera un criterio válido adecuado, qué efecto corresponde exclusivamente a uno y qué a otro. ¿Cómo distinguiríamos, por ejemplo, en qué punto se detiene la labor conocitiva en dirección hacia la "realidad" y empieza la "presencia" pura de ésta, sobre todo teniendo en cuenta que aun el más mínimo e "in-significante" término con que se la señale, es una elaboración, una creación gnoseológica de aquélla? ¿Y cómo podría afirmarse, por cierto, la absoluta exclusividad de la aportación mental en las determinaciones, si no se demuestra por anticipado la no-influencia de la "realidad" sobre las funciones y estructuras mismas determinantes? Para demostrar esto habría que "aislar" Ias estructuras conocitivas, es decir, separarlas de su contenido real; ahora bien, esto no es posible, porque entonces ya no habría conocimiento y aquéllas se reducirian automáticamente a simples formas mentales vacías y el conocimiento se convertiría en pensamiento puro, deducción o combinación ideales, perdiéndose así la distinción específica y fundamental entre ambos: en suma, la no-influencia tiene que comprobarse por necesidad dentro del conocimiento. Pero, de cualquier modo, aunque lo anterior fuera posible, no debe perderse de vista que precisamente de lo que se trata, es de examinar la validez o aplicabilidad conocitiva de tales estructuras, aplicabilidad y validez que sólo pueden comprobarse justamente en el acto mismo de conocer y no prescindiendo de él, pues sería contradictorio.

Tal vez se tenga que responder a todo lo anterior simplemente esto: 
que es una tarea conjunta y complementaria, es decir, que el conocimiento de un objeto real o un objeto real conocido proviene de los dos factores o elementos, sin que sea posible, absolutamente, determinar en concreto la medida y proporción exclusivas de las aportaciones. Así pues, la única afirmación válida es ésta: tiene que haber necesaria e igualmente una aportación conccitiva y una aportación entitativa, pues de otro modo no hay conocimiento; lo que equivale también a decir: pues de otro modo no hay ni conocimiento ni realidad, por la necesaria interdependencia; en suma: o se llega a la afirmación total o se cae en la negación absoluta.

Sin duda, debe admitirse que en el caso de lo aportado por la facultad conocitiva hay un amplio campo para el análisis, el reconocimiento y la descripción, tanto porque se trata del estudio de sí misma, como por la extensión o proporción de lo aportado, que debe concebirse como el máximo, mientras el de la "realidad" es el mínimo -desde luego, dentro de la concepción trascendental. Pero, hay que insistir, en el momento en que se trata de la demostración apodíctica e irrefutable, el lindero de las aportaciones se hace impreciso, porque no existe medio o instrumento alguno que permita captar en forma absoluta lo que la facultad conocente, por un lado, y la "realidad", por otro, son en sí mismas y lo que pueden hacer, prescindiendo de la función conocitiva, puesto que se trata justamente de saber cuál sería la situación fuera del campo o de la influencia relacional del conocimiento: pero esto significaría "sacarlos" de él. Ahora bien, ¿cómo sería ello posible?

De lo anterior puede concluirse que el punto clave de la insolubilidad del problema realismo-idealismo, en lo que se refiere, como hemos repetido, al origen y "Iocalización" de las determinaciones del objeto real conocido, consiste en la necesaria inclusión de los dos elementos conocitivos en el juicio mismo que determinaría o decidiría su procedencia: es decir, toda proposición que afirme una $u$ otra tesis es por necesidad conocimiento, o sólo en el acto de conocer podría decidirse de su alcance y validez; ahora bien, puesto el conocimiento, se presentan de modo necesario acto y contenido, sujeto $y$ objeto, ideas y realidad $-\mathrm{y}$ junto con éstos, naturalmente, las determinaciones-; y al contrario, quitado el conocimiento, desaparecen de manera absoluta los dos factores y las determinaciones (a menos que se admita una facultad conocitiva latente o en potencia: pero entonces el problema se trasladaría al momento de realizarse ésta en acto). ¿Cómo decidir, por tanto, si las determinaciones proceden del acto o del contenido, del sujeto o del objeto, de las formas y estructuras ideales o de la realidad?

Estrictamente hablando no parece posible la existencia de un criterio válido para decidir, pues el argumento absoluto y definitivo sería la comprobación misma de estas dos cosas: 1) de que las formas y estructuras ideales o a priori, causa y origen de las determinaciones, existen, se dan, están 
ahí, independientemente del acto de conocer -como las ideas platónicas en el tópos uránios (¿qué sentido tendrían, si no funcionan como factores conocitivos?)--; y 2) de que las cosas, seres y objetos, poseen en cuanto algo entitativo, de por si e independientemente del acto de conocer, las determinacio. nes mismas. Ahora bien, ¿cómo es posible comprobar esto fuera del acto de conocimiento? ¿Seria posible una comprobación que no fuera conocimiento? En cierta forma deberíamos concebir la posibilidad de una especie de "salida" del conocimiento, para. "comprobar" o "ver", fuera del conocimiento, si las determinaciones están en las cosas o son producto sólo de las estructuras y formas del conocimiento. Esto sólo puede ser una ficción, pues sería afirmar que en un sentido absoluto y estricto se conoce sin conocer.

Permítaseme hacer referencia a un principio de la ciencia física, donde me parece advertir una corroboración de mi punto de vista. Aludo al llamado principio de indeterminación de Heisenberg, que, como es sabido, se funda precisamente en la modificación que sobre el objeto por conocer (electrón, por ej.) produce el medio mismo que se emplea para conocerlo (la luz). Partiendo de aquí, diriamos que en forma parecida, pero como algo mucho más radical, las modificaciones o, más bien, determinaciones, al concebirse como producidas por la facultad conocitiva, impiden saber lo que es en sí la realidad y permiten sólo conocer la realidad modificada por aquélla -en la física se conocerían sólo las partículas modificadas por la luz o por cualquier otro medio de percepción, pero no lo que serían sin ellos, pues entonces no podría en absoluto conocerse la realidad de que se trata: como, en general, la realidad objetiva sin la luz del conocimiento. Así, pues, como la luz ilumina, pero al mismo tiempo indetermina, así la facultad conocitiva hace conocer, pero a la vez deja indeterminado, inconocido, lo que es la realidad en sí. Según el principio de indeterminación, la luz hace conocer las partículas intraatómicas modificadas por ella, es decir, como a ella se le manifiestan y no como son en si sin la modificación producida por la luz, esto es, en la oscuridad, donde no pueden conocerse; según ello, la luz o medios equivalentes "causarían" las modificaciones de las partículas, a saber, sus determinaciones, que es lo que conoce el conocente: Si la realidad no es -o por lo menos no se sabe que es- como se la conoce, entonces la facultad de conocer tiene que modificarla, conocerla equivale a determinarla; mas al determinar su manifestación, como diría Kant, y dejar en la oscuridad absoluta la realidad en sí, que es concebida como "informe", como indeterminada, entonces por lo menos indirectamente la indetermina. El principio de Heisenberg podría sugerir la presencia de un caso particular, así de la inconocibilidad de la verdadera realidad en sí, como de la insolubilidad -aporía- del problema último entre realismo e idealismo.

El punto de vista de la filosofía trascendental - Kant y Fichte- contiene a mi parecer ciertos indicios que apuntan hacia la aporia que he se- 
ñalado, es decir, que pueden considerarse como residuos problemáticos, cuya posible solución indirecta estaría en el reconocimiento de dicha aporía. En Kant serian: a) el enigma, para casi todos insoluble, de la inclusión en su pensamiento de la cosa en si y de los noúmenos; b) la admisión del llamado "conocimiento práctico"; c) la afirmación de la ininvestigabilidad de la probable "raíz común" de las dos "ramas" — sensibilidad y entendimientodel conocer; y d) expresiones como: “... sin objetos, en el mismo [espacio] no se daría absolutamente ninguna representación empírica..." (donde se invalida la función conocitiva $y$, tal vez, la existencia misma del espacio, sin la presencia de los objetos: lo que significaría, 1) negación del conocimiento y, en el fondo, de sus dos elementos, al faltar uno de éstos; y 2) necesidad de la presencia o ausencia conjunta y simultánea de ellos, base de la indeterminabilidad a que alude la aporía). ${ }^{43}$ En Fichte tendriamos: a) la identificación de realidad e idealidad con que remata su pensamiento; $b$ ) la declaración de la existencia de un "círculo" dentro de las bases del problema realismo-idealismo, que lo conduce precisamente a la identificación de las mismas; ${ }^{44}$ c) la amplia argumentación para demostrar que realismo e idealismo en definitiva no pueden refutarse mutuamente en forma directa, "porque su disputa es sobre el primer principio". ${ }^{45}$

No es posible aquí y ahora desarrollar el proceso para demostrar clara y eficazmente el enlace de la afirmación de la aporía con los puntos anteriores, mas en general puede advertirse su dependencia y conexión. Pero, sobre todo, creo que a través de la historia de la gnoseología hay datos implícitos e indirectos para el atisbo de la aporía. ¿Dónde están esos indicios? Para mí, se hallan, en primer lugar, en todas las argumentaciones o actitudes: dogmáticas, escépticas, analíticas, deductivas, ingenuas, científicas, etc., en favor ora del realismo ora del idealismo; en segundo lugar, en todos los problemas, inmediata o mediatamente relacionados, cuya solución, a primera vista obvia y fácil, resulta insegura e insostenible, al profundizarse y llevarse a sus últimas consecuencias.

El reconocimiento pleno de la aporía depende, y dependerá, de la mayor profundidad de la reflexión y mayor sutileza del análisis, así como de una más clara conciencia del alcance del conocimiento humano: lo cual conducirá, sin duda, no al escepticismo, sino a la búsqueda de otros caminos, seguros, aunque no perfectos.

InStituto de INVEstigaciones Filosóficas

BERnabÉ NAVARro Universidad Nacional Autónoma de México 